\title{
TECNOLOGIA DE COMBATE AOS INCÊNDIOS FLORESTAIS
}

\author{
José Carlos Mendes de Morais ${ }^{1}$
}

\begin{abstract}
RESUMO
Ao longo de dez anos de experiência, técnicos do Centro Nacional de Prevenção e Combate aos Incêndios Florestais-Prevfogo/Ibama puderam observar e participar da inovação em termos de contratação de pessoal e de desenvolvimento de tecnologia de equipamentos e ferramentas de combate aos incêndios florestais. A criação de brigadas temporárias em Unidades de Conservação Federal-UC's, trouxe um grande salto de qualidade no desempenho do combate, já que a maioria desses brigadistas são agricultores, moradores locais e profundos conhecedores da região, com notável habilidade em ferramentas manuais; é grande também o benefício social dessas contratações, pois isto gera emprego em regiões remotas, onde estão localizadas a maioria das UC's. O avanço tecnológico dos equipamentos e ferramentas de combate no Brasil vem se desenvolvendo no sentido de dar mais segurança aos brigadistas e maior agilidade ao combate.

Palavras-chave: brigadas; Unidades de Conservação; segurança; equipamentos; ferramentas.
\end{abstract}

\section{TECHNOLOGY SUPPRESSION OF WILDLAND FIRES}

\begin{abstract}
During ten years of experience, technicians of the National Center for Prevention and Suppression of Wildland Fires - Prevfogo/Ibama, could observe and participate in the innovations in terms of contract of personnel and in the development of technologies of equipments and tools for the combat of wildland fires. The establishment of temporary brigades in Federal Conservation Units - UC's brought about a big jump in the quality of the combat performance, since most of these brigades are small farmers, local residents deeply acquaintened with the region and with exceptional ability to deal with handtools; it is also great the social benefits of these contracts, since this generates employment opportunities in the remote regions where most of the UC's are located. The technological advance of equipment and tools for wildland fire combat in Brasil is being developed with the purpose to give more safeness for the brigades and quickness in the combat.
\end{abstract}

Key-words: brigades; Conservation Units, safeness; equipments; tools.

\section{INTRODUÇ̃̃̃O}

$\mathrm{Na}$ década de 80 , órgãos governamentais ambientalistas que deram origem ao Instituto Brasileiro do Meio Ambiente e dos Recursos Naturais Renováveis-Ibama tinham imensas dificuldades em combater incêndios florestais no interior de suas Unidades de Conservação em função da falta de pessoal para executar as tarefas de detecção, controle, rescaldo e vigilância dos incêndios. Os agentes de defesa florestal e outras categorias do quadro eram quase sempre em número insuficiente para atender a demanda, aliado a uma falta de estrutura de logística satisfatória, equipamentos adequados e ferramentas apropriadas. A forma mais eficiente de se Nacional de Prevenção e Combate aos Incêndios Florestais- Prevfogo, com a missão de coordenar ações necessárias à organização, combater incêndios naquela época era com certeza o improviso combinado com uma dedicação exclusiva dos funcionários. Outro fator importante era a localização das Unidades de Conservação, quase sempre distantes dos grandes centros urbanos onde até hoje estão instalados os corpos de bombeiros, que são recrutados, treinados e especializados em incêndios urbanos e, com raras e honrosas exceções, especializados em incêndios florestais. Em função da crescente demanda de incêndios florestais, aliada a falta de estrutura nas Unidades de Conservação-UC's, foi criada a Comissão Nacional de Prevenção e Combate aos Incêndios Florestais-Conacif, que no final dos anos oitenta deu origem ao Sistema implementação e operacionalização das atividades relacionadas com a educação,

1 jose.morais@ibama.gov.br Técnico Prevfogo/Ibama SCEN Trecho 2, edifício sede do Ibama Brasília - DF - 70.800-200 
pesquisa, prevenção, controle e combate aos incêndios florestais e queimadas.

$\mathrm{Na}$ década seguinte, o Prevfogo/Ibama iniciou um momento importante, que foi a qualificação técnica de seus técnicos e de funcionários das Unidades de Conservação$\mathrm{UC}^{\prime}$ 's, envolvendo a troca de experiências e formação de massa crítica em todos os níveis hierárquicos. Para que houvesse essa interação foram estabelecidos vários Acordos de Cooperação Técnica com países mais desenvolvidos no assunto e com experiênciacomprovada na área. Ao longo da década tivemos três importantes acordos que podemos destacar no aperfeiçoamento de pessoal, introdução de novas técnicas e principalmente, no acesso a novas tecnologias de ferramentas e equipamentos. $\mathrm{O}$ Departamento de Agricultura dos Estados Unidos da América, através do seu Serviço Florestal (USDA/FS) ofereceu a brasileiros, entre funcionários do Prevfogo/Ibama, de Unidades de Conservação gerenciadas pelo Ibama, e de oficiais e praças dos corpos de bombeiro militar de vários estados, um programa nos Estados Unidos denominado "Hotshot Crew" (equipes de combate ao fogo), cuja principal finalidade era o aperfeiçoamento de tecnologias na área da prevenção e combate. Esses programas, com duração média de seis meses, foram realizados em diversos locais, como na Floresta Nacional de San Bernardino (San Bernardino National Forest), na Califórnia e constavam de instruções para o preparo de brigadistas no seu condicionamento físico; aulas teóricas e práticas de uso de equipamentos e ferramentas - com ênfase na proteção individual e coletiva; metodologias de prevenção, como a confecção de aceiros; conhecimentos de sistemas meteorológicos, observação e organização para o combate. Após, os instruendos participavam do combate efetivo ao fogo, basicamente na confecção de linhas de controle para o uso de contra-fogo, levando em consideração que a vegetação era quase sempre composta de coníferas, impossibilitando qualquer tipo de combate direto. Apesar de bastante envolvente e prática, lamentavelmente a programação desses cursos não contemplou a parte referente ao processo de recuperação de áreas degradadas pelos incêndios.
Outra importante parceria foi com o Governo Chileno, através da Corporación Nacional Forestal-CONAF, que disponibilizou o engenheiro florestal Juvenal Bosnich, especialista em prevenção e combate a incêndios florestais, para prestar assessoria técnica no Brasil, o qual, em conjunto com o então Coordenador Nacional do Prevfogo, Eng. Florestal PhD Paulo Cézar Mendes Ramos, com larga experiência teórica e prática e que há vários anos vem trabalhando a questão do fogo nas florestas brasileiras, produziu um completo material didático de prevenção e combate aos incêndios florestais, talvez o único disponível no Brasil. Essas apostilas são usadas principalmente por técnicos do Ibama em cursos de formação de brigadas e de queima controlada em todo o território nacional. $\mathrm{O}$ material desenvolvido é composto por oito módulos:

1- Comportamento do Fogo

2- Formação de Brigadas Combate

3- Funções da Organização para o

4- Equipamentos e Ferramentas

5- Combate Terrestre

6- Combate Aéreo

7- Exercícios Práticos

8- Queima Controlada

A partir daí tiveram início os cursos de formação de brigadas voluntárias em várias Unidades de Conservação, criando-se um contingente de mais de cinco mil pessoas com qualificação técnica para exercer qualquer atividade de prevenção e combate aos incêndios florestais, levando em consideração a limitação individual de cada um.

A Agência Española de Cooperación Internacional-EICE, da Dirección General de Conservación de la Naturaleza do Ministério do Meio Ambiente espanhol vem propiciando o intercâmbio de informações entre técnicos de vários países ibero-americanos, inclusive $o$ Brasil, através de cursos e visitas técnicas na área da proteção contra os incêndios florestais.

$\mathrm{Na}$ mesma década houve um grande movimento conservacionista em várias Unidades de Conservação administradas pelo Ibama, com o surgimento de voluntários para executar as atividades de combate aos incêndios florestais. Essas pessoas normalmente eram moradores da própria região, com apego às belezas cênicas que esses 
lugares oferecem e/ou por exercerem a função de condutores de visitantes. Como exemplo, vamos citar o Parque Nacional da Chapada Diamantina, no agreste baiano, que combatia os incêndios sem uma organização básica estruturada e sem qualquer tipo de apoio institucional. O Prevfogo/Ibama firmou um Acordo de Cooperação Mutua com o Grupo Ambientalista da Bahia-GAMBA, que agregava o Grupo Ambientalista de PalmeiraGAP e o Grupo Ambientalista de LençóisGAL, institucionalizando a primeira brigada composta por vinte voluntários, ministrandolhes curso de difusão de técnicas para formação de brigadas, repassando equipamentos de proteção individual-EPI's, ferramentas e equipamentos de combate e fazendo um acompanhamento técnico das atividades de prevenção e combate aos incêndios florestais, contando hoje com mais de 200 voluntários, um verdadeiro exército à disposição da preservação do meio ambiente na região da Chapada Diamantina. No Parque Nacional de Itatiaia/RJ, existia um trabalho exemplar de voluntarismo com o Grupo Excursionista das Agulhas Negras-GERAN, que durante vários anos evitou, combateu e controlou, em conjunto com os funcionários do Parque, os incêndios naquela Unidade de Conservação.

No início do novo milênio o Prevfogo/Ibama foi elevado à categoria de Centro Especializado em Prevenção e Combate aos Incêndios Florestais dentro da estrutura do Ibama, com autonomia técnica administrativa e financeira, e deu início a um programa de remuneração dos serviços de brigadistas, garantido assim uma atividade de prevenção permanente nas UC's nos períodos críticos de ocorrências de incêndios florestais. Buscou meios legais para a contratação e, no ano de 2001, foi possível a contratação da primeira brigada. Essas contratações são por um período de três meses, renováveis por até igual período, contados a partir do treinamento de $40 \mathrm{hs}$ aula entre teoria e prática, passando pela prevenção, como a confecção de aceiros, orientações para o uso do fogo nas áreas limítrofes às Unidades, podendo ir até o combate, e encerrando-se com a chegada das chuvas. Essas brigadas têm fatores fundamentados em filosofia; um dos aspectos relevantes é com certeza a questão social: por estarem as UC's localizadas longe dos grandes centros, com poucas oportunidades de emprego, a contratação de brigadistas nos seis meses que coincidem com o período de estiagem, isto é, na entressafra, quando as atividades agrícolas são pouco desempenhadas, vem gerando novos empregos na região, contribuindo assim com uma ajuda substancial na distribuição de rendas e conseqüentemente incrementando a economia local. Essas contratações, por exigirem toda documentação - que vai da certidão de nascimento até o exame médico, nos faz participar de um importante processo, estimulando o convívio em sociedade, dando dignidade ao agricultor e cidadania no momento em que o mesmo se regulariza perante Órgãos de Governo.

As brigadas são tecnicamente subordinadas ao Centro EspecializadoPrevfogo e administrativamente às Unidades de Conservação a que pertencem, e estão distribuídas nos Parques Nacionais, Florestas Nacionais, Reservas Biológicas, Estações Ecológicas em todas as regiões do Brasil.

Entre os critérios estabelecidos para a seleção de brigadistas, alguns são naturais ou adquiridos por experiência própria do brigadista ao longo de sua vida ou repassadas por seus antepassados, como por exemplo, morar próximo a Unidade, o que facilita sobremaneira o deslocamento dentro da unidade e, conseqüentemente, uma extrema facilidade em se localizar e estabelecer rotas para chegar rapidamente ao local do fogo. Conhecedores dos problemas das UC's, a partir do momento da contratação tornam-se um aliado importante para a proteção da Unidade, funcionando inclusive como agentes multiplicadores. Outro facilitador é a habilidade com que lidam com ferramentas manuais tipo enxada, pá, foice, facão, etc; na sua maioria têm boa resistência física, normalmente adquirida em atividades agrícolas que exigem um esforço contínuo e árduo. Em estudos aplicando realidades de campo, entendeu-se que as brigadas foram idealizadas para atuar com quatorze brigadistas divididos em dois esquadrões de sete, sendo dois Chefes de Esquadrão e um deles o Chefe da Brigada, sempre eleitos pelos integrantes da brigada. $\mathrm{O}$ sete é na numerologia a inteligência e a facilidade de assimilar conhecimentos, e se trata de um número ímpar, de forma que 
sempre era possível uma liderança de forma eletiva e, por fim, era a capacidade máxima dentro de uma Toyota Bandeirante, o veículo mais utilizado pelas Unidades de Conservação na época.

Com a contratação das brigadas aumentou o número de pessoas em campo, trazendo mais riscos à integridade física e ao stress mental. Preocupado com isso, o Ibama começou a investir em equipamentos de proteção individual-EPI's, para garantir a segurança dos brigadistas e estimular a indústria nacional na pesquisa, confecção e disponibilizacão no mercado de EPI's adequados. Nos equipamentos obrigatórios repassados às brigadas temos: botas em couro e solado de borracha com cano alto; calças e gandolas confeccionadas em brim resistente nem sempre antichamas (nomex), que só são fornecidos aos combatentes com vínculo permanente com o Prevfogo devido ao alto custo; camisetas em algodão, que proporcionam conforto através da absorvição de suor; luvas em vaqueta de couro; capacetes ejetados em uma única peça e óculos especiais para proteção dos olhos. As cores foram cuidadosamente escolhidas, dando um contraste com todo tipo de ambiente florestal: a cor amarela do capacete e da gandola contrasta com o verde das matas, e o verde da calça contrasta com o cinza do cerrado seco. Qualquer semelhança com as cores oficiais do Brasil ou nacionalismo extremo é mera coincidência.

Em função do tamanho das Unidades de Conservação, aliado ao fato de que as brigadas, por serem federais, podem ser deslocadas para outras Unidades ultrapassando limites municipais, avançando divisas estaduais para dar apoio em combate ampliado inclusive por solicitação de outras Unidades da Federação, apoiando a Corpos de Bombeiros e/ou Defesas Civis Estaduais e Nacional, o Centro Especializado Prevfogo adquiriu unidades móveis de combate - os "Rodofogo", planejados por seus próprios técnicos a fim de facilitar o deslocamento de brigadistas com algum conforto e equipamentos agregados para facilitar o combate. Os Rodofogo possuem itens de conforto como bancos reclináveis, arcondicionado e freezer, entre outros, para propiciar um descanso em viagens longas. Esses veículos também estão equipados com tanque de 1.000 lt de água potável que pode ser utilizado tanto para consumo humano como para limpeza em geral, uma moto-bomba de sucção para o enchimento do reservatório e lançamento de água para uso no combate direto ao incêndio, quando possível. A geração de energia é feita por um gerador que tem condições de iluminar toda a área do acampamento, inclusive com dois holofotes que são acoplados na parte superior do baú. Possuem também uma bomba elétrica que aciona água para o uso de chuveiro, e pode ser montada do lado externo. Esses equipamentos são fixos nos caminhões, podendo ser retirados sempre que necessário para montagem de acampamentos. Os veículos possuem ainda armários vazados para condicionamento de equipamentos, ferramentas e material de acampamento, podendo estabelecer bases avançadas de combate para vinte brigadistas. Levando-se em consideração que os rodofogos são limitados em função do tamanho e peso para acesso em estradas mal conservadas, a cada Unidade de Combate é disponibilizado um veículo tipo utilitário $4 \mathrm{X} 4$ munido com todos os meios de comunicação, que faz o trabalho de transporte dos brigadistas, equipamentos, ferramentas e alimentação até o local mais próximo do incêndio, evitando-se assim longas caminhadas.

A utilização de ferramentas é sempre condicionada a cada tipo de combate levandose em consideração a estratégia adotada em relação a vegetação existente, a topografia identificada e as questões meteorológicas, que também devem ser observadas para que se faça a escolha certa das ferramentas e equipamentos, evitando-se desta forma o desperdício de energia nos combates e no transporte.

Para o combate eram conhecidas as ferramentas raspantes e as cortantes, que tiveram uma evolução necessária, inclusive criando novas categorias que são as duplas e as múltiplas. Embora as ferramentas duplas e múltiplas estivessem disponíveis a vários anos no mercado, a liga do ferro e o material utilizado para o cabo deixavam a desejar, bem como a qualidade do acabamento. As raspantes utilizadas, como a enxada e o ancinho, são extremamente úteis na confecção e manutenção de linhas de controle ou aceiros, com uma única desvantagem: a utilização de 
duas ferramentas demanda dois combatentes ou um combatente com duas ferramentas, o que torna pouco produtivo $\mathrm{o}$ trabalho $\mathrm{e}$ dificulta o transporte. Com a chegada das ferramentas duplas, ou seja, com a combinação de duas ferramentas conjugadas como o McLeod - que tem num dos lados a enxada e no outro o ancinho, em um único movimento de rotação o combatente troca o lado da peça, trabalhando ao mesmo tempo com as duas ferramentas. Por sua grande utilidade, foi assim eliminado o problema, embora a relação custo-benefício esteja longe da realidade brasileira. Como o Brasil dispõe de grandes áreas de cerrado foi criado o abafador, que veio substituir com muita propriedade os galhos, a palmeira e outros materiais utilizados para suprimir o oxigênio do fogo, quebrando assim uma das arestas do conhecido triângulo do fogo; por se tratar de uma ferramenta multiuso, o abafador é também utilizado para quebrar galhos e rebaixar vegetação e, aproveitando a extensão do cabo, mantém uma distância segura das labaredas. Outra ferramenta multiuso imprescindível em qualquer tipo de combate a incêndios florestais é a pá, que pode ser utilizada em toda a sua performance raspando, cavando, cortando, etc.

Os equipamentos desenvolvidos e disponíveis dão agilidade, ganham tempo e dão conforto nos combates: a moto-serra substitui o machado, a bomba costal facilita $o$ resfriamento de materiais incandescentes, seja no combate ou no rescaldo. Atualmente vem sendo testado um atomizador com motor a dois tempos, acrescido de dispositivo para combate aos incêndios florestais denominado pelo fabricante/montador com "Turbo Sopro". O motor desse equipamento aciona uma ventoinha em um sistema de turbina que gera um vento forte conforme a aceleração, que é canalizada através de um tubo cilíndrico que direciona o jato de ar para as chamas, ocasionando seu resfriamento e fazendo um efeito de vento contrário empurrando as chamas para a área já queimada, ocasionando a extinção do fogo, podendo ainda ser agregado água por gravidade; essa água aspergida que facilita o resfriamento do material em chamas, tornando mais eficiente e rápido o combate. Todo o conjunto, ventoinha, motor $\mathrm{e}$ reservatórios de água e combustível, é fixado em duas alças sobre o ombro do operador no formato de uma mochila. Outro equipamento, que vem se agregando aos pouco e já está tomando dimensões quase que imprescindíveis em todos os incêndios de médio e grande porte, é a utilização de meios aéreos, seja como plataforma de observação, de transporte de combatentes e equipamentos ou no combate direto, utilizando compartimentos adaptados, no caso de aviões agrícolas, ou sacos apropriados (helibaldes) para helicópteros. A utilização de tratores tem sido cada vez menor devido a degradação deixada que, dependendo da avaliação do técnico coordenador do combate, pode causar um dano ambiental maior e de mais difícil recuperação do que as marcas deixadas pelos incêndios.

Para estabelecer bases avançadas de combate, houve a necessidade de se melhorar as condições de infraestrutura dos acampamentos. Por sugestão dos combatentes, foram confeccionadas barracas grandes com capacidade para abrigar até quinze combatentes ou acondicionar grande volume de equipamentos, ferramentas ou gêneros alimentícios para manutenção do combate sem que haja uma intervenção externa, que se torna demorada e onerosa; outro estudo do caso levou à necessidade de se adquirir barracas individuais e redes de selva, desta forma ficando-se preparados para qualquer tipo de situação.

A comunicação local entre os combatentes à distância, fazendo a ponte entre a coordenação do incêndio e o Centro Especializado/Sede, que pode providenciar meios para efetivar um combate ampliado, exige que todas as unidades à disposição da prevenção e combate aos incêndios florestais do Prevfogo estejam equipados com modernos meios de comunicação, como rádios tipos HT, "Hi Transmision", para distâncias curtas entre brigadistas e viaturas, com alta fidelidade na transmissão e recepção, embora de alcance limitado, dependendo de barreiras naturais como árvores, serras, etc. ou artificiais como muros, obras, entre outros obstáculos que possam impossibilitar a propagação de ondas. Para transmissão e recepção de dados à longa distância, está sendo utilizado um sistema via satélite chamado "Auto Trac", disponível nas viaturas do Prevfogo e em alguns veículos do Ibama. Esse equipamento encontra-se também disponível em caixas transportáveis que podem 
ser alimentadas por baterias, e outra maneira de se acessar o sistema é via Internet o que, inclusive, possibilita verificar visualmente em bases de dados georeferenciados a posição exata do elemento receptor/transmissor.

O Centro Especializado Prevfogo vem difundindo aos Órgãos Estaduais de Meio Ambiente, Polícias Técnicas, peritos criminais e Corpos de Bombeiros, técnicas que possibilitam localizar as origens e chegar às causas dos incêndios florestais. A determinação de origem e causas dos incêndios florestais não tem como finalidade única e exclusiva a identificação de possíveis infratores, mas serve principalmente para se trabalhar as causas dos incêndios florestais, podendo retro-alimentar um sistema mais eficiente de prevenção e eliminar potenciais riscos de incêndios florestais.
Pode-se concluir que a criação das brigadas é com certeza uma das atividades mais nobres que o Ibama vem desenvolvendo desde a sua criação, mostrando uma preocupação na manutenção de suas Unidades de Conservação em todas as categorias, preservando não apenas a flora e a fauna, mas todo um banco genético, pois provavelmente existem espécies ainda não catalogadas ou mesmo desconhecidas no meio técnicocientífico. Equipamentos e ferramentas tiveram um desenvolvimento para melhoria na qualidade do combate, buscando sempre um rápido ataque inicial e extinção dos incêndios florestais. Todo esse aparato, seja humano ou material, é observado, adaptado ou desenvolvido e disponibilizado ao longo dos anos; igualmente, a busca de causas dos incêndios e seus efeitos tem colaborado para tornar mais efetivo um sistema nacional de prevenção e combate aos incêndios florestais. 